\title{
mHealth Conceptual Model for Providing Quality Antenatal Care in Health Centers during the Coronavirus Disease 2019 Pandemic
}

\author{
Delmaifanis Delmaifanis $^{1 *(\mathbb{D})}$, Kemal Siregar $^{2}$ D, Artha Prabawa $^{2}$ \\ ${ }^{1}$ Department of Reproductive Health, Faculty of Public Health, University of Indonesia, Depok, West Java, Indonesia; \\ ${ }^{2}$ Department of Biostatistics and Population, Faculty of Public Health, University of Indonesia, Depok, West Java, Indonesia
}

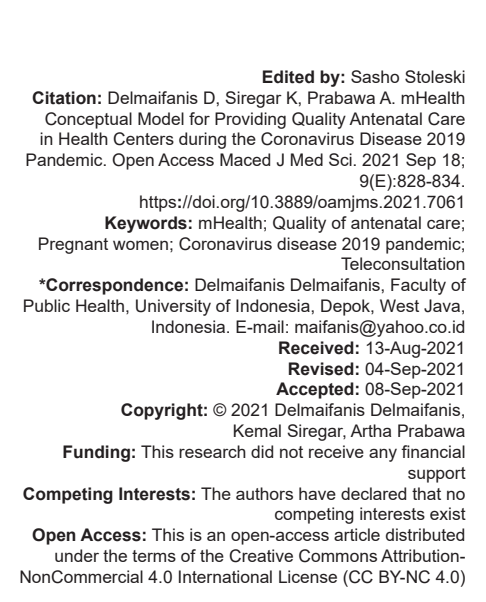

\section{Introduction}

One of the goals of the Sustainable Development Goals is to reduce the Maternal Mortality Rate (MMR) and the target to be achieved in 2030 is $<70 / 100,000$ live births. Meanwhile, the MMR is estimated to be $211 / 100,000$ live births, or there are 295,000 maternal deaths every year in the world [1]. Meanwhile, in Indonesia, 2015 data show a high MMR of 305 per 100,000 live births, where this figure has not decreased significantly over the past decades [2].

The direct causes of maternal death are complications that occur during pregnancy and the puerperium. Furthermore, the most common complications that account for about $75 \%$ of deaths are bleeding, infection, pre-eclampsia, prolonged labor, and unsafe abortion [1]. Besides, there are indirect causes of maternal death at the community level, referred to as late 3 (3T), such as late recognition of danger signs, late referrals, and late optimal service [3]. The delay in recognizing danger signs is due to the mother's lack of knowledge about it and this has resulted in the late arrival and late referral at health services, such that at the time of referral, the condition was already in a critical state and finally no help could be rendered when she arrived at the hospital [4].

One of the efforts to prevent maternal mortality is through antenatal examination, which aims to prepare mothers for childbirth and infant care. An interesting phenomenon is an increase in antenatal care (ANC) coverage, but it does not lead to a significant decrease in MMR. This condition seems to indicate the low quality of ANC. Meanwhile, its standard in Indonesia is 10T which includes, an examination of height and weight, blood pressure examination, upper arm circumference measurement, uterine fundal height measurement, examination of heart rate and fetal position, screening and administration of TT, routine laboratory examination, administration of Fe and Folic Acid, case management, and interviews (counseling), but only $4 \%$ were found to provide 7-10T services [5].

The quality of ANC is a determining factor in reducing maternal morbidity and mortality [6]. Furthermore, a gap between its standard and the services received by pregnant women makes the service less effective and therefore requires a mechanism to monitor the quality of ANC [7]. Factors related to the quality of ANC are the competence of officers, retraining, and the availability of complete 
equipment [4], [6]. Other things that play a role in the quality of ANC are supervision, interprofessional cooperation, and the existence of security guarantees for service officers, especially at night and in vulnerable areas [8], [9], [10].

Most health workers that provide antenatal services at the health centers are midwives. Furthermore, the health centers are first-level facilities, and the government has made efforts to make them accessible and affordable to everyone. Health centers also coordinate and foster all health facilities in their working area [11].

The coronavirus disease 2019 (COVID-19) pandemic has severely disrupted ANC due to large-scale social distancing and (PSBB) policies. It was reported that $10 \%$ of health centers' services stopped, while at the community level, $75 \%$ of Posyandu were closed, $41 \%$ of home visits were stopped, and $46 \%$ of antenatal services at Posyandu stopped [12]. However, pregnant women are reluctant to go to health service facilities for fear of contracting COVID-19. As a result, it is, therefore, necessary to change the pattern of ANC following the current conditions of the COVID-19 pandemic.

The use of internet-based technology is beneficial in increase the efficiency and productivity of work, with automation facilitating work processes and communication between individuals from different places. One of the applications of this technology in the health sector is mHealth, which can improve officers' performance, the quality of ANC, and the coverage of these services. Furthermore, the use of mHealth during pregnancy has a positive effect on the increase in knowledge, motivation, and behavior of mothers in ANC [13], [14]. Furthermore, it also useful as an early detection tool for pregnancy risk, therefore assisting service providers in providing adequate ANC [15].

This study aims to design the mHealth concept to improve the quality of ANC, to add features that support service workers during the COVID-19 pandemic. The new in this modeling compared to the previous mHealth is that several features are developed in a single application, whereby supporting the functional relationship between pregnant women, midwives, maternal and child health $(\mathrm{MCH})$ coordinator at health centers, and health offices.

\section{Methods}

The research method used is as follows:

1. Literature study in the form of a scoping review A literature review was conducted on the factors that influence the quality of ANC

2. Conceptual design of the mHealth model according to the Rapid Application
Development approach, in which the following steps are taken [16]:

a. Designing features to improve the quality of ANC based on the results of a literature study

b. Designing the mHealth context diagram for ANC

c. Designing the mHealth interface that midwives will primarily use.

\section{Results}

\section{Literature study}

It was found from the ProQuest, Springer Link, and Google scholar database that the factors influence the low quality of ANC and the potential for improvement with mHealth. The results of this literature study are summarized in Table 1, and the information from this table is then used to design the mHealth model.

Table 1: Factors affecting the low quality of ANC and potential improvement with mHealth

\begin{tabular}{|c|c|c|c|}
\hline $\begin{array}{l}\text { Factors affecting the low } \\
\text { quality of ANC }\end{array}$ & Reference & $\begin{array}{l}\text { Potential increase with } \\
\text { mHealth }\end{array}$ & Reference \\
\hline $\begin{array}{l}\text { Lack of knowledge, skills, } \\
\text { lack of communication skills } \\
\text { of officers }\end{array}$ & [17], [18] & $\begin{array}{l}\text { Clinical decision aids, early } \\
\text { detection of pregnancy } \\
\text { complications }\end{array}$ & {$[19],[20],[21]$} \\
\hline $\begin{array}{l}\text { Excess workload, availability } \\
\text { of visit times }\end{array}$ & [22], [23] & $\begin{array}{l}\text { Send messages to } \\
\text { pregnant women, provide } \\
\text { health promotion materials, } \\
\text { provide information }\end{array}$ & [15] \\
\hline Lack of practice & [24], [25] & $\begin{array}{l}\text { Strengthen health } \\
\text { promotion, send messages } \\
\text { to officers }\end{array}$ & [26] \\
\hline $\begin{array}{l}\text { Lack of facilities and } \\
\text { infrastructure }\end{array}$ & [10], [27] & $\begin{array}{l}\text { Compliance with standard } \\
\text { operating procedure (SOP) }\end{array}$ & [20] \\
\hline $\begin{array}{l}\text { Low level of officer compliance } \\
\text { and lack of supervision }\end{array}$ & [28] & $\begin{array}{l}\text { SOP compliance and } \\
\text { notification when there are } \\
\text { SOPs that have not been } \\
\text { implemented }\end{array}$ & [20] \\
\hline $\begin{array}{l}\text { Lack of access for pregnant } \\
\text { women to health facilities, } \\
\text { lack of cooperation between } \\
\text { officers }\end{array}$ & [29], [30] & $\begin{array}{l}\text { Teleconsultation and } \\
\text { mapping of the geographic } \\
\text { location of pregnant women }\end{array}$ & [31] \\
\hline
\end{tabular}

ANC: Antenatal care.

\section{Designing the mHealth model}

Features to improve the quality of ANC

There are nine mHealth features designed to improve the quality of ANC, which are as follows:

\section{Adherence to SOPs for ANC \\ 2. Digital health records \\ 3. Clinical decision aids \\ 4. Referral link \\ 5. Strengthen health promotion \\ 6. Alerts and reminders \\ 7. Real-time reports \\ 8. Teleconsultation \\ 9. Distribution map of pregnant women.}

mHealth is equipped with artificial intelligence that uses expert systems to improve the quality of 
ANC, and also to display clinical decision aids, such as the detecting of risk factors in pregnant women and possible diagnoses and recommendations for handling cases for officers. Pregnant women also conduct risk detection against themselves based on the data filled in mHealth. For pregnant women by entering the data of last menstruation, mHealth automatically processes the estimated date of delivery and gestational age, as well as recommendations for pregnancy care.

\section{Context diagram of mHealth ANC}

Four external mHealth entities were designed, which includes, pregnant women, midwives, $\mathrm{MCH}$ health centers coordinators, and health offices. The external entities that function as mHealth data providers are pregnant women and midwives, while those which functions as recipients of $\mathrm{mHealth}$ reports are the $\mathrm{MCH}$ coordinators at health centers and health offices.

Meanwhile, mHealth is in the middle and functions to organize as well as integrate incoming data. Furthermore, the context diagram shows how data flows from mHealth. Furthermore, the arrows show the flow of data or information to and from mHealth and external entities. Diagrammatically, the mHealth context for ANC is shown in Figure 1.

\section{mHealth interface}

The mHealth system interface design includes input (form design) and output (dashboard design) interfaces. mHealth is designed to use a Progressive Web application; hence, the appearance of the mobile application is different from that on the web platform, and there are also differences for each group of users. In addition, the individual components are shown in Figure 1. To ensure the security and confidentiality of thus it is not used by, each user group displays a different menu depending on their role. Furthermore, each user is provided with a password. Therefore, before logging in, they must select their role on mHealth and then register. Meanwhile, when registering pregnant women the ID number is used as a unique code to differentiate them. For midwives and doctors, fill in the STR or SIP, which indicates that they already have a license to practice.

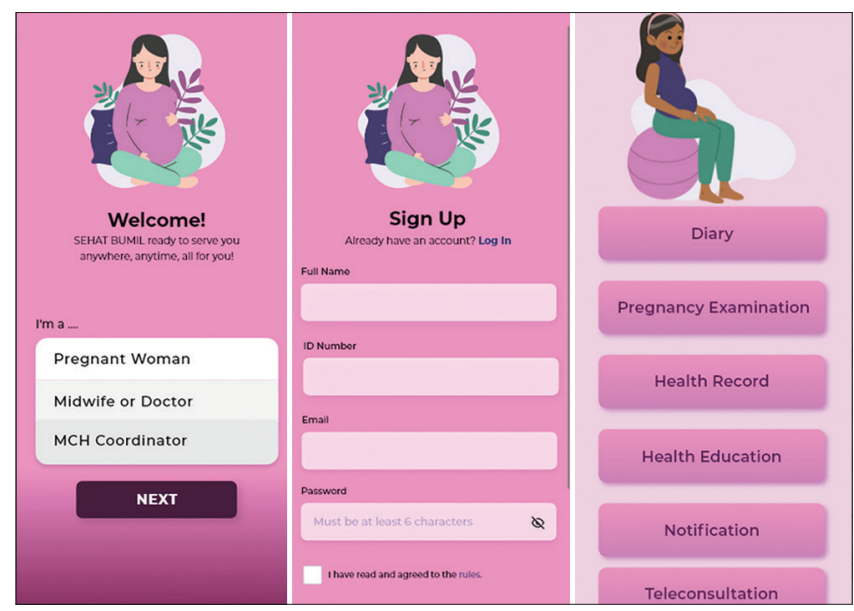

Figure 2: The menu shows the role of users as pregnant women

Figure 2 shows the design of the mHealth interface for mobile application users, such as pregnant women. Furthermore, features that are accessible to mothers include registration, filling in pregnancy history data, maternal health records, notifications, health education, and recommendations. After users have registered and logged in, their appropriate menu is been chosen by them, in which the data entry feature is used to complete the previous pregnancy and maternal health history. The medical records for medical history during pregnancy follow the services of the facilities in which the antenatal examinations are conducted. In addition, the notification feature is a reminder of the schedule for re-examining pregnant women and taking health medication, including advice and information on pregnancy care and preparation for delivery.

Figure 3 shows several menus that midwives use to support health services for pregnant women. The

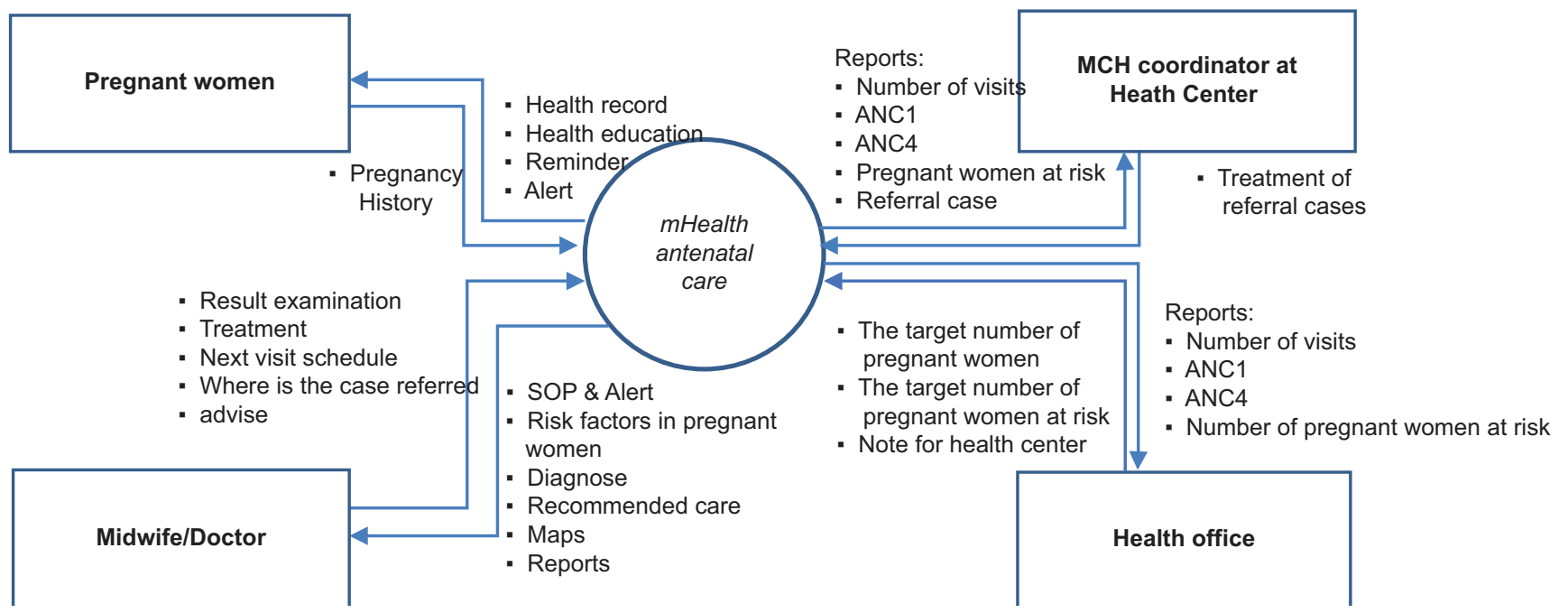

Figure 1: Context diagram of mHealth antenatal care 
mHealth for midwives is designed to manage maternal health programs, from the arrival of the pregnant women to completion of services, and contains all routine records. Furthermore, the midwifery menu includes examinations, medication, referrals, reports, and maps of pregnant women, and the examination menu provides all the necessary assessment tools during $\mathrm{ANC}$, which helps midwives present complete data. The report menu is helpful for monitoring services and as a daily or monthly report that would be accessed in real-time. Besides, there is also a cohort of pregnant women that midwives use to describe the mother's health status during pregnancy.
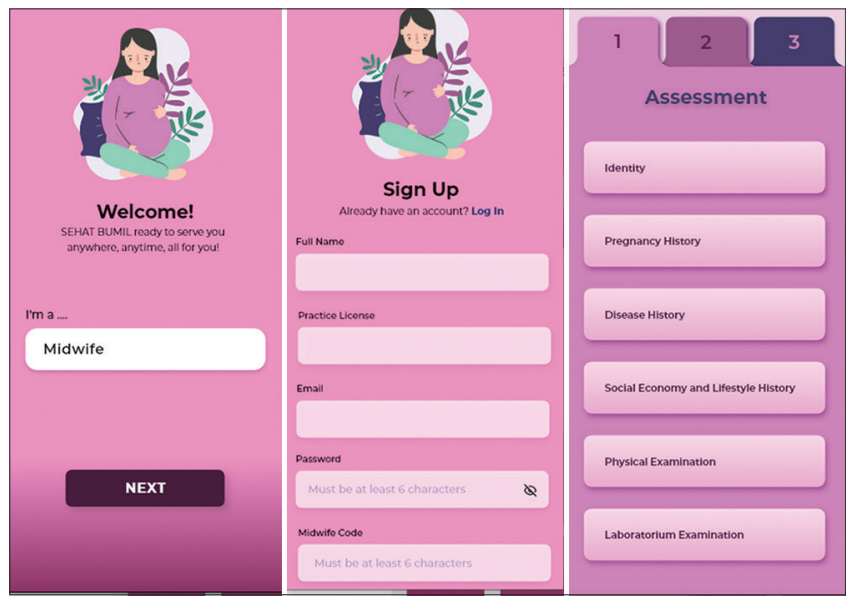

Figure 3: mHealth menu for midwives

A distribution map for pregnant women is helpful for the $\mathrm{MCH}$ Coordinator and the Health Office to know where pregnant women are at risk and to monitor the achievements and performance of the maternal health service program in each midwife that practices independently in the sub-district health centers.

\section{Discussion}

Quality ANC is needed to improve the ability of pregnant women to care for pregnancy and prepare for delivery. Based on the literature study, several factors influence the low quality of ANC. The literature study also reveals the potential and the nine features of $\mathrm{mHealth}$ that improve the quality of ANC.

The compliance feature of SOP guides health workers in its consistent implementation, and mHealth warns if the staff does not comply with the 10T standard of service. Data show that the percentage of pregnant women who received 7-10T services at the ANC4 visit was $2 \%$, and most pregnant women (68\%) only received 1-4T services [32]. Furthermore, the same report was provided by other studies, which found a low implementation of the 10T service standard, such as $4 \%$, where the least service received by pregnant women was counseling at $23 \%$, whereas ANC4 visits had reached $85 \%$ [33].

Pregnant women require health record feature as pregnancy history, and when there is a record pregnant women's health records (PHR), the health of pregnant women should be better monitored [15]. Thus far, the recording of maternal health in the mother's book ( $\mathrm{MCH}$ book) was successfully carried out. Data from the National Health Survey (Sirkesnas) in 2016 show that the distribution of $\mathrm{MCH}$ books has reached $94 \%$ of regions in Indonesia, $81.5 \%$ of pregnant women already have them, but only $60.5 \%$ of pregnant women are able to show their $\mathrm{MCH}$ books. In addition, only $18 \%$ of these books were filled [34]. With PHR on smartphones always carried by pregnant women, it is hoped that these health records will be filled and also increases the mother's knowledge because of the habit of pregnant women who often open their smartphones. The Health Record feature also presents a list of questions for pregnant women about pregnancy and medical history, as well as health complaints that pregnant women feel.

Al with expert systems displays clinical decisions based on knowledge and logic to present new facts and recommendations following existing data in the system [35]. Based on the user's answers to questions in the system, it will provide conclusions and recommendations using the IF-THEN rules. The feature is expected to solve the imbalance of officers' competence or the lack of focus in providing services because it was discovered that the competence of health workers is not as expected [36]. Therefore, having mHealth support with clinical decision aids in ANC improves staff skills and increases pregnant women's participation and trust in health workers [21].

The referral link helps in communication between health workers or facilities, thereby speed up the referral process hence pregnant women receive faster services. When midwives refer patients to health centers, the goal is to receive notification and details of referred cases. When patients arrive, they can be served immediately. Therefore, this link also assists $\mathrm{MCH}$ managers in monitoring referral cases and as a program evaluation tool [31].

Strengthening health promotion is needed to empower pregnant women by increasing knowledge and preparation for childbirth. Furthermore, the limited time for midwives to conduct visits makes the information conveyed during the visit incomplete. Therefore, the health promotion features are prepared to help pregnant women get correct information about their pregnancy, prepare them for childbirth, and involve husbands and families [26].

Alerts and reminders are required for pregnant women and midwives. In the case of midwives, this warning will appear when they forget or do not implement 10T ANC standards also when there are data on the risk of pregnant women. In addition, the reminder notifies pregnant women to visit and schedule for medication/vitamins. Furthermore, one of them 
includes iron (Fe), which pregnant women should be consumed daily. The data show the low compliance of pregnant women in consuming $\mathrm{Fe}$.

Real-time reports simplify the work of service personnel by eliminating the need to manually create various kinds of records and reports. In the past, officers have always been bothered by writing various notes, thus consuming a lot of staff time and wasting paper. With mHealth, there will be the automation of recording and reporting work [15]. Therefore, it becomes easier for managers and health offices to monitor and evaluate, thereby eluding cases of late reporting, as well as finding out the map of pregnant women at risk and facilitate planning for program development.

The teleconsultation feature facilitates communication between pregnant women and midwives, therefore specific reasons that prevent pregnant women from visiting takes advantage of this feature either because of access difficulty or other reasons, thereby enabling them to consult through chat or video call. The difference between this feature and other chat or video call applications is that when chatting or video calling, the midwife knows the health history of pregnant women based on their health records on $\mathrm{mHealth}$ to provide the right advice.

During the COVID-19 pandemic, the provision of maternal services needs to be a concern to avoid increasing maternal morbidity and mortality. The existence of the risk of COVID-19 transmission makes pregnant women worried about visiting health services. Based on reports, there has been a decrease in physical visits by pregnant women to health facilities, as well as guidelines from the Ministry of Health to reduce non-urgent visits of pregnant women to service facilities [12]. Meanwhile, a decrease in antenatal visits reduces ANC1 and ANC4 performance from the nine features designed for mHealth. Therefore, teleconsultation and health promotion strengthening features are expected to be very useful during the COVID-19 pandemic and in new normal conditions.

In anticipation of a deterioration in services for pregnant women during the COVID-19 pandemic, the government has issued service guidelines for both those suspected to be infected and non-infected with COVID-19 pregnant women (People Under Monitoring category, People Without Symptoms), or Patients Under Supervision) or those who have been confirmed to have COVID-19 infection [37]. Innovation in antenatal services is needed to provide services and maintain their quality during a pandemic. In this case, mHealth antenatal services, especially the teleconsultation feature, are deemed necessary.

The problems of pregnant women during the COVID-19 pandemic were partially resolved with the teleconsultation feature. When a pregnant woman that is positive for COVID-19 without or with mild symptoms undergoes self-isolation, the presence of mHealth antenatal services makes it easier to monitor this. Furthermore, when the case is not an emergency, but the pregnant woman needs a consultation, one alternative is a virtual visit. Therefore, they are being consulted from home using the teleconsultation feature.

Despite the social distance, pregnant women will be provided with information or advice about pregnancy care and preparation for childbirth with the health promotion features available on mHealth. The feature reduces a mother's chances of receiving misinformation from social media or believing in myths that affect her pregnancy.

\section{Conclusion}

The design of the mHealth concept is supported by features that are considered to improve the quality of ANC, which include, SOP compliance, maternal health records, clinical decision aids, referral links, teleconsultation, strengthening health promotion, alerts, and reminders, real-time reports, and maps distribution of pregnant women.

During the COVID-19 pandemic, mHealth antenatal services provided significant support to pregnant women and their staff, especially with the teleconsultation feature, which allows close communication between pregnant women and midwives to maintain access to ANC services still. Meanwhile, another important feature here that is a continuation of teleconsultation is the health promotion strengthening feature. Considering this result, the mHealth conceptual model for antenatal is to be continued as a prototype for physical application.

\section{References}

1. World Health Organization, UNICEF, UNFPA, World Bank Group, Division UNP. Trends in Maternal Mortality 2000 to 2017 Estimates by WHO, UNICEF, UNFPA, World Bank Group and the United Nations Population Division. Sexual and Reproductive Health. World Health Organization; 2019. p. 122. Available from: https://www.who.int/reproductivehealth/publications/maternalmortality-2000-2017/en. [Last accessed on 2021 Mar 12].

2. Kementerian Kesehatan, BKKBN, BPS, USAID. Indonesia Demographic and Health Survey 2017. Jakarta: BKKBN; 2018.

3. Respati SH, Sulistyowati S, Nababan R. Analysis of determinants of maternal mortality in Sukoharjo Regency, Central Java, Indonesia. J Kesehat Reproduksi. 2019;6(2):52.

4. Salem A, Lacour O, Scaringella S, Herinianasolo J, Benski AC, Stancanelli G, et al. Cross-sectional survey of knowledge of obstetric danger signs among women in rural Madagascar. BMC Pregnancy Childbirth. 2018;18(1):46. https://doi.org/10.1186/ s12884-018-1664-x

PMid:29402226 
5. Hendarwan H, Laestari KF, Hananto M. Quality of antenatal examination services by midwives at health centers. Bul Penelit Kesehat. 2018;46(2):97-108.

6. Oladapo OT, Osiberu MO. Do sociodemographic characteristics of pregnant women determine their perception of antenatal care quality? Matern Child Health J. 2009;13(4):505-11. https://doi. org/10.1007/s10995-008-0389-2

PMid:18629621

7. Hodgins S, D'Agostino A. The quality-coverage gap in antenatal care: Toward better measurement of effective coverage. Glob Heal Sci Pract. 2014;2(2):173-81. https://doi.org/10.9745/ ghsp-d-13-00176

PMid:25276575

8. Pricilla R, David K, Siva R, Vimala T, Rahman S, Angeline N. Quality of antenatal care provided by nurse midwives in an Urban health centre with regard to low-risk antenatal mothers. Indian J Community Med. 2017;42(1):37-42. https://doi. org/10.4103/0970-0218.199796

PMid:28331252

9. Ubra M. Analisis Faktor Yang Berhubungan Dengan Kinerja Bidan Puskesmas Kabupaten Fakfak Dalam Memberikan Pelayanan Antenatal; 2006. p. 169. https://doi.org/10.33087/ jiubj.v19i1.545

10. Mugo NS, Dibley MJ, Damundu EY, Alam A. Barriers faced by the health workers to deliver maternal care services and their perceptions of the factors preventing their clients from receiving the services: A qualitative study in South Sudan. Matern Child Health J. 2018;22(11):1598-606. https://doi.org/10.1007/ s10995-018-2555-5

PMid:29956127

11. Kementerian Kesehatan RI. Regulation of the Minister of Health of the Republic of Indonesia No. 43 of 2019 concerning Health Centers. BPK RI, 49 Indonesia: BN.2019/NO.1335, PERATURAN.GO.ID: 40 HLM; 2019. p. 1-159. Available from: https://peraturan.bpk.go.id/Home/Details/138635/permenkesno-43-tahun-2019 [Last accessed on 2021 Mar 12].

12. Kemenkes, UNICEF. Health Rapid Assessment Report: Background of Essential Health Services during the COVID-19 Pandemic in Indonesia; 2020.

13. Choi JW, Lee JH, Vittinghoff E, Fukuoka Y. mHealth physical activity intervention:Arandomized pilot study in physically inactive pregnant women. Matern Child Health J. 2016;20(5):1091-101. https://doi.org/10.1007/s10995-015-1895-7

PMid:26649879

14. Modi D, Dholakia N, Gopalan R, Venkatraman S, Dave K, Shah $\mathrm{S}$, et al. MHealth intervention "ImTeCHO" to improve delivery of maternal, neonatal, and child care services-A cluster-randomized trial in tribal areas of Gujarat, India. PLoS Med. 2019;16(10):e1002939. https://doi.org/10.1371/journal. pmed.1002939

PMid:31647821

15. Wagnew F, Dessie G, Alebel A, Mulugeta H, Belay YA, Abajobir AA, et al. Does short message service improve focused antenatal care visit and skilled birth attendance? A systematic review and meta-analysis of randomized clinical trials. Reprod Health. 2016;15(7):191. https://doi.org/10.1186/ s12978-018-0635-z

PMid:30466453

16. Dennis A, Haley BW, Roth RM. System analysis and Design. $5^{\text {th }}$ ed. United States: Wiley; 2012.

17. Freeman $\mathrm{H}$, Newland LA, Coyl DD. New directions in father attachment. Early Child Development and Care. 2010;180:1-8. https://doi.org/10.1080/03004430903414646

18. Ruwayda. Implementation of antenatal service standards by midwives at the Jambi city health center. Indonesian Public Health Media. 2016;12(2):91-7.
19. Sondaal SF, Browne JL, Amoakoh-Coleman M, Borgstein A, Miltenburg AS, Verwijs M, et al. Assessing the effect of mhealth interventions in improving maternal and neonatal care in low and middle-income countries: A systematic review. PLoS One. 2016;11(5):e0154664. https://doi.org/10.1371/journal. pone. 0154664

PMid:27144393

20. Borsari L, Stancanelli G, Guarenti L, Grandi T, Leotta S, Barcellini $\mathrm{L}$, et al. An innovative mobile health system to improve and standardize antenatal care among underserved communities: A feasibility study in an Italian hosting center for asylum seekers. J Immigr Minor Health. 2018;20(5):1128-36. https://doi.org/10.1007/s10903-017-0669-2

PMid:29143900

21. Abejirinde $I O$, Douwes $R$, Bardají A, Abugnaba-Abanga $R$, Zweekhorst M, van Roosmalen J, et al. Pregnant women's experiences with an integrated diagnostic and decision support device for antenatal care in Ghana. BMC Pregnancy Childbirth. 2018;18:209. https://doi.org/10.1186/s12884-018-1853-7

22. Rahmani $Z$, Brekke $M$. Antenatal and obstetric care in Afghanistan a qualitative study among health care receivers and health care providers. BMC Health Serv Res. 2013;13:166. https://doi.org/10.1186/1472-6963-13-166

23. Gamelia E, Sistiarani C, Masfiah S. Determinants of pregnancy care behavior. Kesmas Natl Public Health J. 2013;12:3465. https://doi.org/10.21109/kesmas.v8i3.358

24. Rurangirwa AA, Mogren I, Ntaganira J, Govender K, Krantz G. Quality of antenatal care services in Rwanda: Assessing practices of health care providers. BMC Health Serv Res. 2018;18:865. https://doi.org/10.1186/s12913-018-3694-5

25. Gudu W, Addo B. Factors associated with utilization of skilled service delivery among women in rural Northern Ghana: A cross sectional study. BMC Pregnancy Childbirth. 2017;17:159. https://doi.org/10.1186/s12884-017-1344-2

26. Rassi C, Gore-Langton GR, Walimbwa BG, Strachan CE, King R, Basharat $S$, et al. Improving health worker performance through text messaging: A mixed-methods evaluation of a pilot intervention designed to increase coverage of intermittent preventive treatment of malaria in pregnancy in West Nile, Uganda. PLoS One. 2018;13(9):e0203554. https://doi. org/10.1371/journal.pone.0203554

27. Phommachanh S, Essink DR, Jansen $M$, Broerse JE, Wright $P$, Mayxay M. Improvement of quality of antenatal care (ANC) service provision at the public health facilities in lao PDR: Perspective and experiences of supply and demand sides. BMC Pregnancy Childbirth. 2019;19(1):1-14. https://doi.org/10.1186/ s12884-019-2345-0

28. Patria A, Amatiria G. The relationship between the quality of antenatal services and the completeness of pregnant women in performing antenatal care. J IIm Keperawatan Sai Betik. 2018;14(1):108. https://doi.org/10.26630/jkep.v14i1.1017

29. Mikrajab MA, Rachmawati T. Policy analysis of integrated antenatal care implementation at public health centers in Blitar city. Bul Penelit Sist Kesehat. 2016;19(1):41-53. https://doi. org/10.22435/hsr.v19i1.4988.41-53

30. Mattern E, Lohmann S, Ayerle GM. Experiences and wishes of women regarding systemic aspects of midwifery care in Germany: A qualitative study with focus groups. BMC Pregnancy Childbirth. 2017;17:389. https://doi.org/10.1186/ s12884-017-1552-9

31. Nyati-Jokomo Z, Dabengwa IM, Makacha L, Nyapwere $N$, Dube YP, Chikoko L, et al. RoadMApp: A feasibility study for a smart travel application to improve maternal health delivery in a low resource setting in Zimbabwe. BMC Pregnancy Childbirth. 2020;20:1-12. https://doi.org/10.1186/s12884-020-03200-7

32. Dharmayanti I, Azhar K, Hapsari D, H PS. Quality Pregnancy Checkup Services that are Used by Pregnant Women to 
Prepare for Childbirth in Indonesia; 2019. p. 60-9.

33. Saptarini II, Suparmi S. Utilization and completeness of antenatal care services in Kebon Kalapa Village, Bogor City in 2014. Bul Penelit Kesehat. 2016;44(3):6-9. https://doi.org/10.22435/bpk. v44i3.4960.173-180

34. Kemenkes RI. National Report on Basic Health Research 2018. Jakarta: Badan Penelitian dan Pengembangan Kesehatan; 2019.

35. Hoffman JM, Dunnenberger HM, Hicks JK, Caudle KE, Carrillo MW, Freimuth RR, et al. Developing knowledge resources to support precision medicine: Principles from the clinical pharmacogenetics implementation consortium (CPIC).
J Am Med Informatics Assoc. 2016;23(4):796-801. https://doi. org/10.1093/jamia/ocw027

PMid:27026620

36. Silviana S, Darmawan ES. Analysis of competency standards for health workers at Bhakti Yudha Hospital Depok in 2017. J ARSI. 2017;4(1):35-47. [Last accessed on 2021 Mar 12]. Available from: http://journal.fkm.ui.ac.id/arsi

37. Yulianti A. Maternal services during the Covid-19 Pandemic. Quality of health services. Yogyakarta; 2020. Available from: http://www. mutupelayanankesehatan.net/3460-Iayananmaternal-di-masa-pandemi-covid-19-pengalaman-rsup-sardjitodiypandemic covid. https://doi.org/10.2139/ssrn.3828387 